\title{
Simultaneous and Sequential Development of Sixth Nerve Palsy and Horner's Syndrome from Carotid Cavernous Sinus Fistulas
}

\author{
Po Hsiang (Shawn) Yuan ${ }^{a}$ Jonathan A. Micieli ${ }^{b, c, d}$ \\ aFaculty of Medicine, University of British Columbia, Vancouver, BC, Canada; ${ }^{b}$ Department of \\ Ophthalmology and Vision Sciences, University of Toronto, Toronto, ON, Canada; 'Division \\ of Neurology, Department of Medicine, University of Toronto, Toronto, ON, Canada; \\ ${ }^{\mathrm{d} K e n s i n g t o n}$ Vision and Research Centre, Toronto, ON, Canada
}

Keywords

Sixth nerve palsy $\cdot$ Horner's syndrome $\cdot$ Carotid cavernous sinus fistula

\begin{abstract}
The combination of ipsilateral sixth nerve palsy (6NP) and Horner's syndrome (Horner's) is a localizing sign of an injury to the posterior cavernous sinus. The presentation and clinical course of 3 patients presenting with coexisting ipsilateral 6NP and Horner's as a result of carotid cavernous sinus fistulas (CCFs) are discussed in this case series. We highlight these cases to show the possible sequence of events: (i) simultaneous discovery of $6 \mathrm{NP}$ and Horner's, (ii) 6NP followed by Horner's, and (iii) Horner's followed by 6NP. It is important to carefully assess for Horner's in patients with 6NP as this has high localizing value. In patients with a red eye consistent with a CCF, identifying Horner's also has high localizing value and can confirm the suspicion of a CCF. Clinicians should recognize that although 6NP and Horner's localize to the cavernous sinus and may be due to a CCF, they may appear in isolation or sequentially. It is also important to understand that Horner's and 6NP have different prognoses: 6NP usually resolves over time, whereas Horner's tends to persist.
\end{abstract}




\section{Case Reports in Ophthalmology}

\section{Introduction}

The finding of coexisting sixth nerve palsy (6NP) and Horner's syndrome (Horner's) should prompt neuroimaging with careful attention to the cavernous sinus as this combination is highly localizable to this area [1]. Previously described pathologies in this area include neoplasms (e.g., nasopharyngeal carcinoma), carotid cavernous aneurysms, and carotid cavernous sinus fistulas (CCFs) [2-10]. While there are previous published cases on CCFs causing 6NP with Horner's, the sequence of events (sequential 6NP and Horner's vs. simultaneous) and long-term outcomes still remain to be clarified. This case series demonstrates that 6NP and Horner's may appear simultaneously or sequentially in patients with CCFs. Although 6NP has a good prognosis, Horner's tends to persist.

\section{Case 1}

A 34-year-old healthy man presented with a right red eye for 5 months. He was repeatedly unsuccessfully treated for conjunctivitis by multiple eye care providers. The redness worsened, and he noticed new horizontal binocular diplopia 1 week prior to presentation. His initial examination revealed preserved visual acuity, IOP of 29 OD and 18 OS, right ptosis, miosis, and limitation of abduction (Fig. 1). Pharmacologic testing with apraclonidine $0.5 \%$ showed reversal of right anisocoria after $1 \mathrm{~h}$, consistent with Horner's. CT angiography (CTA) of the head showed signs consistent with a right spontaneous CCF including an enlarged tortuous superior ophthalmic vein. The indirect low flow fistula was supplied arterially by the inferolateral trunk of the internal carotid artery (ICA) and cavernous branches of the external carotid artery, draining into the right cavernous sinus. He unsuccessfully underwent multiple attempted embolizations due to difficulty accessing the facial vein. Definitive treatment occurred with a procedure which involved a right frontotemporal craniotomy to cannulate the superior ophthalmic vein. His diplopia and conjunctival changes resolved after 1 month. The right Horner's persisted at the 12-month follow-up.

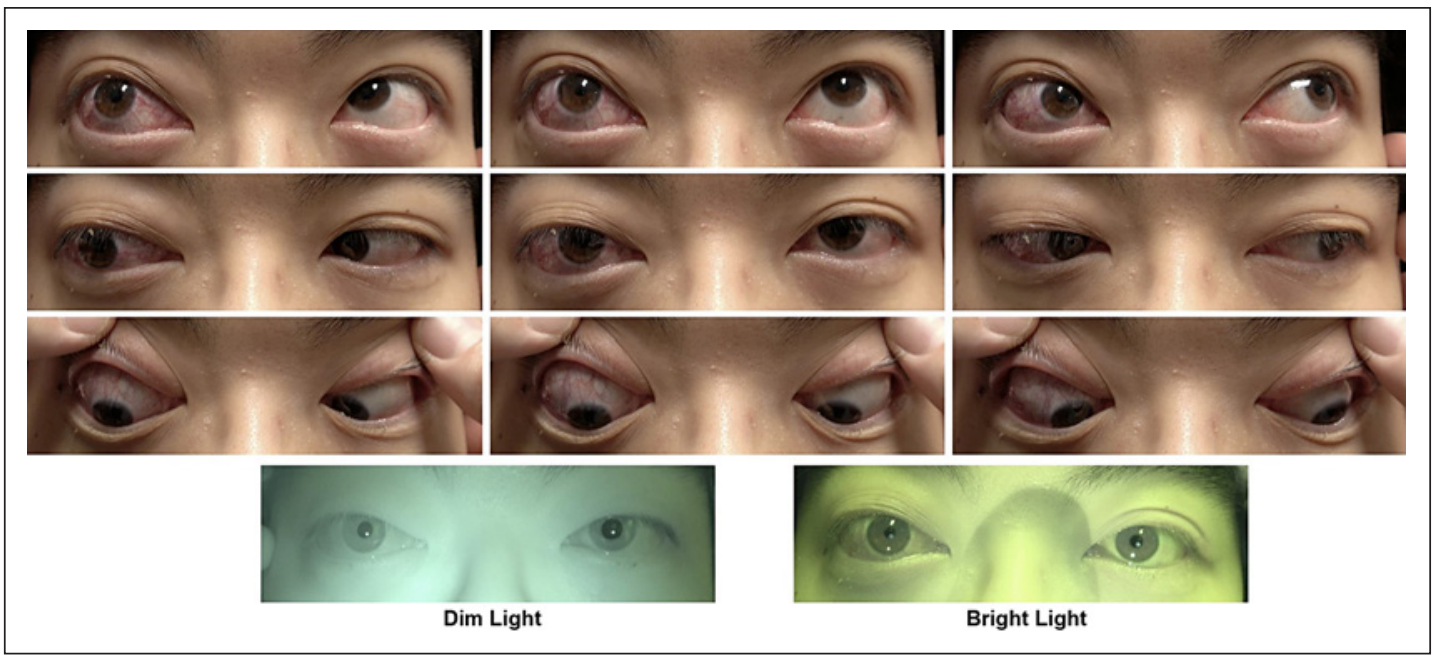

Fig. 1. Initial external examination of a healthy 34-year-old man presenting with simultaneous coexisting right 6NP and right Horner's arising from an ipsilateral CCF. 


\section{Case Reports in Ophthalmology}

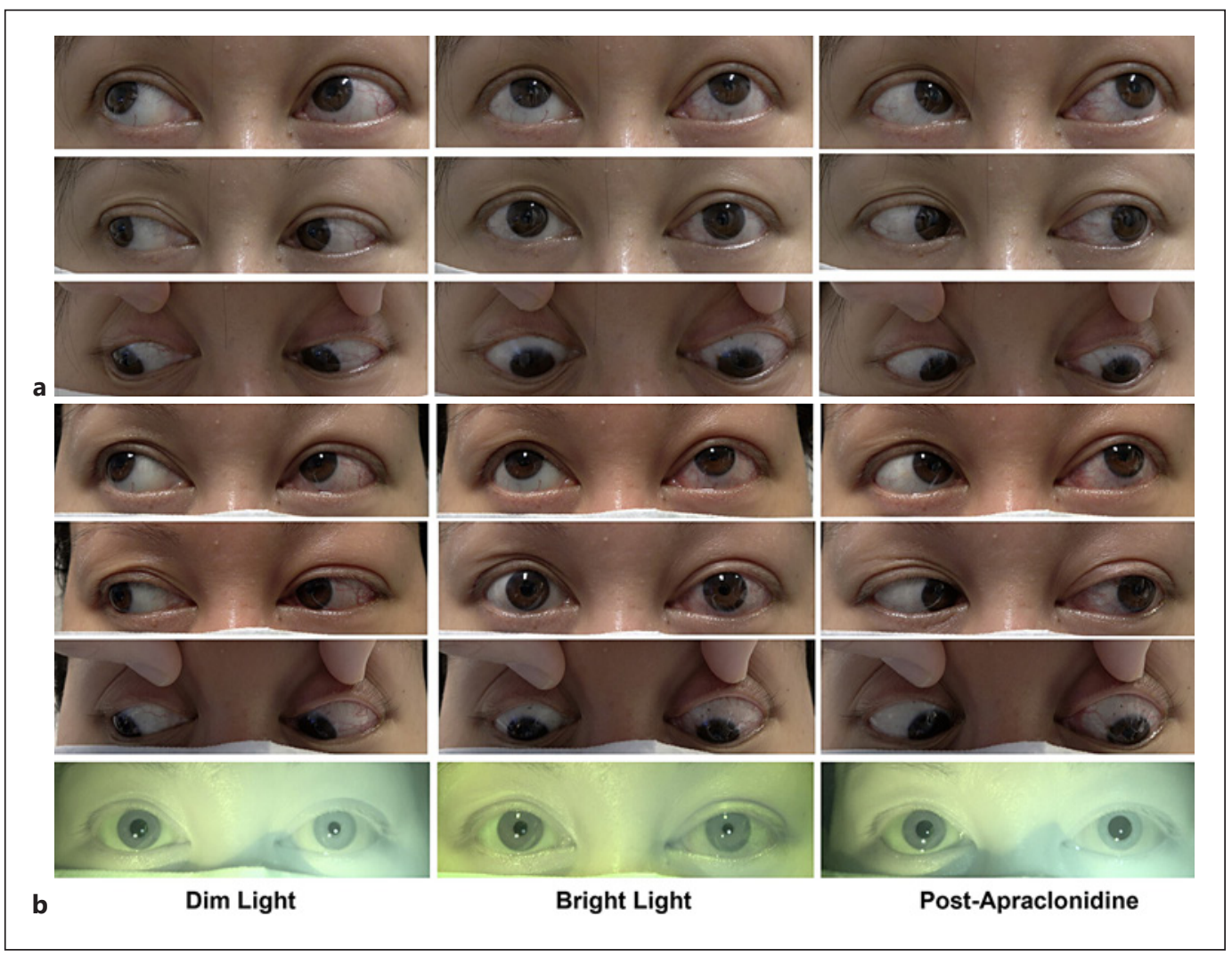

Fig. 2. a Initial external examination of a healthy 44-year-old woman who presented with left 6NP. Re-examination 5 days later (b), after she developed new ptosis, miosis, and corkscrew episcleral vessels. Reversal of miosis with apraclonidine $0.5 \%$ helped diagnose new left Horner's.

\section{Case 2}

A 44-year-old healthy woman presented with a 3-month history of left-ear pulsatile tinnitus and new binocular horizontal diplopia, starting 1 week prior to presentation. Examination revealed preserved visual acuity, IOP of 14 OD and 22 OS, a left abduction deficit, and symmetric, reactive pupils (Fig. 2a). CTA of the head showed asymmetry in the cavernous sinuses (larger on left) and a tortuous intracavernous blood vessel which opacified coincident with carotid arteries. Five days after presentation, she developed new left ptosis, miosis, and conjunctival injection (Fig. $2 b$ ). The anisocoria reversed with apraclonidine $0.5 \%$, consistent with a new left Horner's. She underwent digital subtraction angiography which confirmed a spontaneous direct CCF. This fistula connected the posterior wall of the left ICA to the superior ophthalmic vein, inferior petrosal sinus, intracavernous sinus, and subsequently the contralateral cavernous sinus and petrosal system. There was no cortical venous reflux. She subsequently underwent successful endovascular coiling of the left direct CCF. Follow-up 2 weeks later showed resolution of 6NP and conjunctival change, but left Horner's persisted at 6-month follow-up.

\section{Case 3}

A 72-year-old woman was seen in neuro-ophthalmology consultation for right eye redness and ptosis lasting 1 month. She had a past medical history of osteoporosis, and she took risedronate. Visual acuity was 20/25 OD and 20/20 OS, and there was right conjunctival injection, 


\section{Case Reports in Ophthalmology}

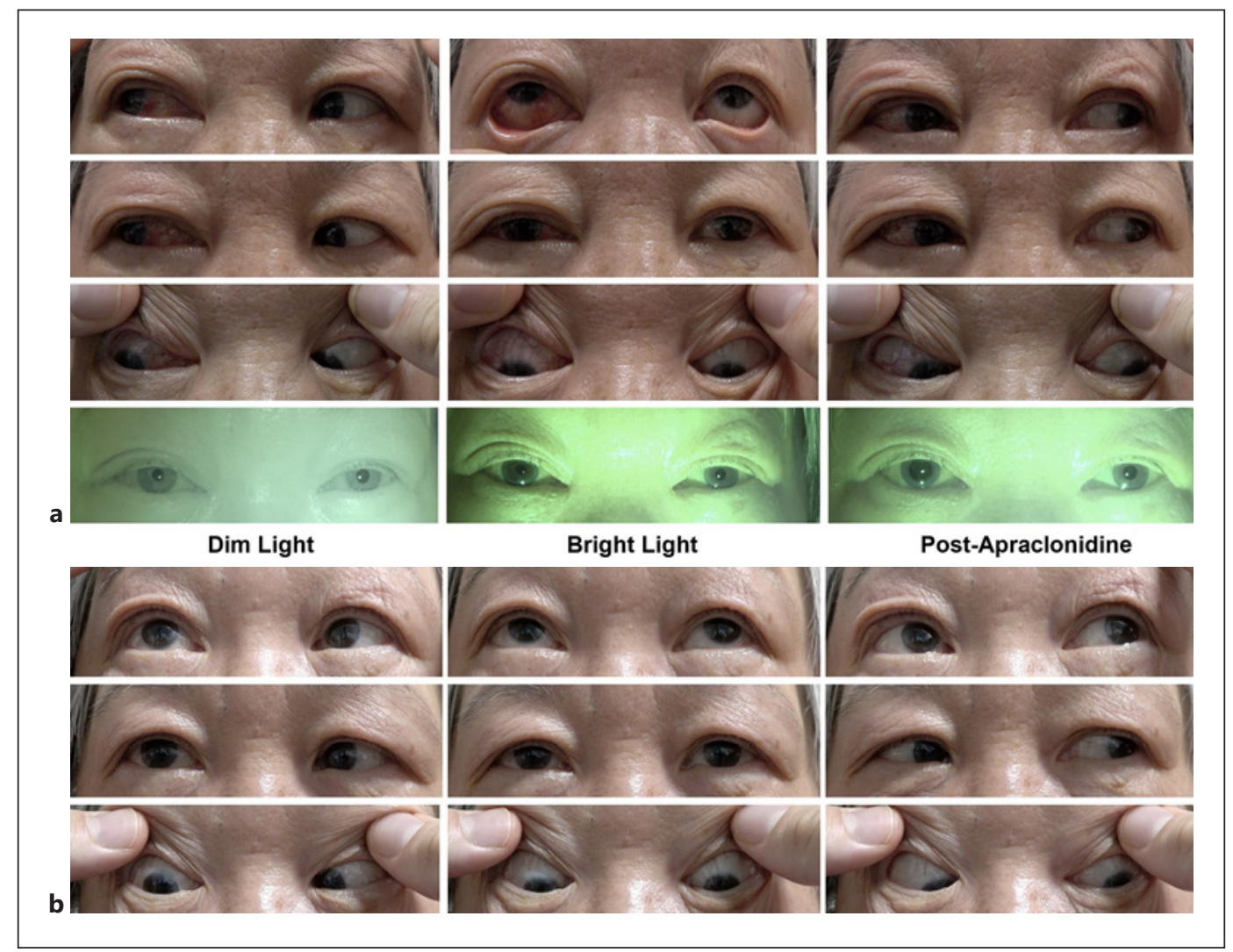

Fig. 3. a Initial external examination of a 72-year-old woman who presented with right red eye, miosis, and ptosis. Reversal of miosis with apraclonidine $0.5 \%$ helped diagnose Horner's related to a CCF. Re-examination 1 day after successful coiling of a fistula (b), demonstrating a new ipsilateral abduction limitation. Horner's was unchanged.

mild right ptosis, and miosis (Fig. 3a). The anisocoria reversed $1 \mathrm{~h}$ after instillation of apraclonidine $0.5 \%$. She underwent CTA of the head that showed an enlarged right superior ophthalmic vein and small flow voids in the right cavernous sinus. She underwent digital subtraction angiography that showed a right-sided indirect low flow CCF connecting branches of the right maxillary artery to a dilated right superior ophthalmic vein. There was no intracranial venous reflux. She underwent successful endovascular coiling and 1 day later noticed new binocular horizontal diplopia and examination revealed a right abduction limitation (Fig. 3b). The right conjunctival injection and diplopia improved then resolved over the course of 6 months, while Horner's persisted.

\section{Discussion}

The presence of ipsilateral Horner's and 6NP is highly localizable because the oculosympathetic nerve fibres responsible for Horner's travel for only a few millimetres alongside the ipsilateral sixth cranial nerve in the posterior cavernous sinus [1,5]. Previous pathologies known to cause this combination include intracavernous ICA aneurysms and neoplastic growths such as nasopharyngeal carcinoma, petrous apex fractures, and CCFs [2-10]. These are summarized in Table 1.

Our literature review revealed no prior cases of Horner's with red eye from a CCF and only 4 previous cases describing the presentation of $6 \mathrm{NP}$ alongside Horner's in the context of 
Yuan and Micieli: Sixth Nerve Palsy and Horner's in CCFs

Table 1. Summary of reported cases of coexisting ipsilateral 6NP and Horner's

\begin{tabular}{|c|c|c|c|c|c|}
\hline Reference & Age/Sex & Pathology & Side & Treatment & Outcome \\
\hline Batawi et al. [2] & $74 / F$ & SCC & $\mathrm{L}$ & Radiation & $\begin{array}{l}\text { Stable neurological } \\
\text { exam }\end{array}$ \\
\hline \multirow[t]{2}{*}{ Gutman et al. [3] } & $50 / F$ & Carotid aneurysm & $\mathrm{L}$ & Clamping & $\begin{array}{l}\text { Incomplete } \\
\text { recovery of } 6 \mathrm{NP}\end{array}$ \\
\hline & $47 / F$ & $\begin{array}{l}\text { Metastatic breast } \\
\text { carcinoma }\end{array}$ & $\mathrm{R}$ & Radiation & Unspecified \\
\hline \multirow[t]{2}{*}{ Striph et al. [4] } & $74 / F$ & $\begin{array}{l}\text { Intracavernous carotid } \\
\text { aneurysm }\end{array}$ & $\mathrm{L}$ & Declined surgery & $\begin{array}{l}\text { Worsened ptosis, } \\
6 \mathrm{NP} \text {, and new V1 } \\
\text { numbness }\end{array}$ \\
\hline & $30 / \mathrm{M}$ & $\begin{array}{l}\text { Pituitary adenoma } \\
\text { (GH-producing) }\end{array}$ & $\mathrm{R}$ & Surgical resection & Persisting 6NP \\
\hline Kang et al. [5] & $68 / \mathrm{M}$ & Nasopharyngeal SCC & $\mathrm{R}$ & Surgical resection & $\begin{array}{l}\text { Cancerous cachexia } \\
\text { leading to death }\end{array}$ \\
\hline Abad et al. [6] & $18 / \mathrm{F}$ & Traumatic aneurysm & $\mathrm{R}$ & Declined surgery & $\begin{array}{l}\text { Persisting 6NP and } \\
\text { Horner's }\end{array}$ \\
\hline Fujisawa et al. [7] & $70 / \mathrm{M}$ & Traumatic CCF & $\mathrm{L}$ & Occlusion & $\begin{array}{l}\text { Persisting 6NP, } \\
\text { Horner's and mild } \\
\text { facial numbness }\end{array}$ \\
\hline Kal et al. [8] & $22 / \mathrm{M}$ & Traumatic CCF & $\mathrm{R}$ & Unspecified & Unspecified \\
\hline Zhuang et al. [9] & $84 / F$ & Spontaneous CCF & $\mathrm{L}$ & Embolization & $\begin{array}{l}\text { Persisting } 6 \mathrm{NP} \text { and } \\
\text { Horner's }\end{array}$ \\
\hline Kim et al. [10] & $68 / F$ & $\begin{array}{l}\text { History of resolved } \\
\text { traumatic CCF from } \\
10 \text { years ago }\end{array}$ & $\mathrm{L}$ & Strabismus surgery & $\begin{array}{l}\text { Resolved 6NP, } \\
\text { persisting Horner's }\end{array}$ \\
\hline
\end{tabular}

All cases involve pathologies localized to the posterior cavernous sinus.

SCC, squamous-cell carcinoma.

a CCF [7-10]. In each of these cases, 6NP and Horner's were simultaneously discovered. None of these patients had an immediate complication following CCF repair, as seen with the new $6 \mathrm{NP}$ in case 3 . However, there are reports of 6NPs developing or worsening after successful coilings of the CCFs [11-16]. Depending on the specific mechanism involved, 6NP may present immediately post-coiling or have a delayed onset [10-13]. New 6NPs may develop from the mass effect of coils causing direct compression or damage of the sixth nerve and the development of thrombophilic nidus around the coil, resulting in chronic inflammation or ischaemia around the sixth nerve $[11,13]$. Worsening of an existing 6NP after endovascular coiling may be observed from strabismus decompensation, gradually worsening compression, or an altered perfusion from the dorsal meningeal artery which supplies the sixth cranial nerve [10, $11,13]$. These risks should be communicated to patients, and they should receive long-term follow-up even after complete neurological and radiological recovery. In a case series of 73 patients undergoing coil embolization for CCF, 4 patients (5.5\%) experienced a delayed onset and persisting 6NP [15]. A risk factor for persisting post-coiling 6NP is the overpacking of coils in the cavernous sinus and can be mitigated by adhering to cut-off values of coil volumes [14-16].

In most cases of coexisting Horner's and 6NP arising from non-CCF aetiologies, these findings were simultaneously discovered. This emphasizes the importance of carefully examining the pupils in patients with diplopia related to 6NP. However, one previous case from nasopharyngeal 
carcinoma had a delayed finding of Horner's 3 weeks after initial presentation with 6NP [5]. The growth of this cancer through the sphenoid sinus demonstrated by a PET scan showed direct compression on the sixth cranial nerve, which lies superior to the oculosympathetic nerve along the lateral wall of the posterior cavernous sinus [5]. This may explain the delayed presentation of Horner's in addition to the significantly larger calibre sixth nerve when compared to the oculosympathetic fibres. Although it was reported that both 6NP and Horner's persisted 10 weeks after initial presentation, long-term outcomes were unavailable due patient death [5].

There is a lack of reported long-term outcomes in CCF-related coexisting 6NP and Horner's to guide the prognosis of symptoms important to patients. In a case series of CCF patients presenting with isolated ophthalmoplegia (no Horner's), 3/15 (20\%) patients had persisting 6NP after endovascular CCF repair [17]. Our case series adds to the limited reports of combined 6NP and Horner's seen in the context of CCFs and offers some prognostic outcomes from long-term follow-up. The persistence of Horner's after successful treatment of CCFs may be explained by the characteristics of oculosympathetic fibres responsible for Horner's [1-4]. Damage to these very thin and friable fibres is rarely completely reversible, and in our cases, there was likely lasting disruption of these oculosympathetic fibres.

In conclusion, Horner's and 6NP may be simultaneously or sequentially discovered due to CCFs. Our cases demonstrate that 6NP has an excellent prognosis after CCF repair, whereas Horner's is likely to persist.

\section{Statement of Ethics}

Written informed consent was obtained from each patient for publication of this case report and any accompanying images. This study protocol was reviewed, and the need for approval was waived by the University of Toronto Research Ethics Board. This retrospective review of patient data did not require ethical approval in accordance with local/national guidelines.

\section{Conflict of Interest Statement}

The authors have no perceived or potential conflicts of interest to declare.

\section{Funding Sources}

This manuscript did not receive any funding from any sources.

\section{Author Contributions}

Conception and design: P.H.Y. and J.A.M.; data acquisition: P.H.Y. and J.A.M.; manuscript preparation: P.H.Y. and J.A.M.; and final approval: P.H.Y. and J.A.M. All the authors have seen and approved the final version of the manuscript for publication.

\section{Data Availability Statement}

All data generated or analysed during this study are fully presented or referenced in this article. Further enquiries can be directed to the corresponding author. 


\section{References}

1 Parkinson D, Bernard M. Bernard, Mitchell, Horner syndrome and others? Surg Neurol. 1979;11:221-3.

2 Batawi H, Micieli JA. Nasopharyngeal carcinoma presenting as a sixth nerve palsy and Horner's syndrome. BMJ Case Rep. 2019 Oct 1;12(10):e232291.

3 Gutman I, Levartovski S, Goldhammer Y, Tadmor R, Findler G. Sixth nerve palsy and unilateral Horner's syndrome. Ophthalmology. 1986 Jul 1;93(7):913-6.

4 Striph GG, Burde RM. Abducens nerve palsy and Horner's syndrome revisited. J Clin Neuroophthalmol. 1988 Mar 1;8(1):13-7.

5 Kang NH, Lim KH, Sung SH. Horner's syndrome with abducens nerve palsy. Korean J Ophthalmol. 2011 Dec; 25(6):459.

6 Abad JM, Alvarez F, Blazquez MG. An unrecognized neurological syndrome: sixth-nerve palsy and Horner's syndrome due to traumatic intracavernous carotid aneurysm. Surg Neurol. 1981 Aug 1;16(2):140-4.

7 Fujisawa H, Marukawa K, Kida S, Hasegawa M, Yamashita J, Matsui O. Abducens nerve palsy and ipsilateral Horner syndrome: a predicting sign of intracranial carotid injury in a head trauma patient. J Trauma. 2001 Mar 1;50(3):554-6.

8 Kal A, Ercan ZE, Duman E, Arpaci E. Abducens nerve palsy and ipsilateral horner syndrome in a patient with carotid-cavernous fistula. J Craniofac Surg. 2015 Oct 1;26(7):e653-5.

9 Zhuang I, Kini A, Al Othman B, Lee AG. Abducens nerve palsy and ipsilateral Horner syndrome as the presenting finding of carotid cavernous fistula. Can J Ophthalmol. 2019 0ct 1;54(5):e247-9.

10 Kim WJ, Moon CW, Kim MM. Delayed onset abducens nerve palsy and horner syndrome after treatment of a traumatic carotid-cavernous fistula. J Korean Ophthalmol Soc. 2019 Sep 1;60(9):905-8.

11 Kalaichandran S, Micieli JA. Bilateral sixth nerve palsies from carotid cavernous fistulas with transient worsening following transvenous embolisation. BMJ Case Rep. 2019 Nov 1;12(11):e232191.

12 Hayashi K, Horie N, Morikawa M, Nagata I. Usefulness of C-stopper Coil for Neurointervention. Neurologia medico-chirurgica; 2013.

13 Ghannam AB, Subramanian PS. Delayed onset cranial nerve palsies after endovascular coil embolization of direct carotid-cavernous fistulas. J Neurophthalmol. 2018 Jun 1;38(2):156-9.

14 Nishino K, Ito Y, Hasegawa H, Kikuchi B, Shimbo J, Kitazawa K, et al. Cranial nerve palsy following transvenous embolization for a cavernous sinus dural arteriovenous fistula: association with the volume and location of detachable coils. J Neurosurg. 2008 Aug 1;109(2):208-14.

15 Kashiwazaki D, Kuwayama N, Akioka N, Kuroda S. Delayed abducens nerve palsy after transvenous coil embolization for cavernous sinus dural arteriovenous fistulae. Acta Neurochir. 2014 Jan;156(1):97-101.

16 Kohta M, Fujita A, Tanaka J, Sasayama T, Hosoda K, Kohmura E. Novel segmentation of placed coils in the treatment of cavernous sinus dural arteriovenous fistulas provides a reliable predictor of the long-term outcome in abducens nerve palsy. World Neurosurg. 2018 May 1;113:e38-44.

17 Leonard TJ, Moseley IF, Sanders MD. Ophthalmoplegia in carotid cavernous sinus fistula. Br J Ophthalmol. 1984 Feb 1;68(2):128-34. 